\title{
Short-term Service-Learning: Implications for Preparing Health Science Students for Practice
}

\author{
Tamara Lemmonds \\ Belmont University, tamara.lemmonds@belmont.edu \\ Jamie Adam \\ Belmont University, jamie.adam@belmont.edu \\ Elena Wong Espiritu \\ Belmont University, Elena.espiritu@belmont.edu \\ David K. Wyant \\ Belmont University, david.wyant@belmont.edu
}

Follow this and additional works at: https://nsuworks.nova.edu/ijahsp

Part of the Medicine and Health Sciences Commons

\section{Recommended Citation}

Lemmonds T, Adam J, Espiritu EW, Wyant DK. Short-term Service-Learning: Implications for Preparing Health Science Students for Practice. The Internet Journal of Allied Health Sciences and Practice. 2021 Oct 01;19(4), Article 3.

This Manuscript is brought to you for free and open access by the College of Health Care Sciences at NSUWorks. It has been accepted for inclusion in Internet Journal of Allied Health Sciences and Practice by an authorized editor of NSUWorks. For more information, please contact nsuworks@nova.edu. 


\title{
Short-term Service-Learning: Implications for Preparing Health Science Students for Practice
}

\begin{abstract}
Purpose: The purpose of this paper is to examine students' self-reported learning outcomes following participation in collaborative interprofessional service-learning experiences through the qualitative analysis of participants' written, guided critical reflections. Method: Participants responded to guided reflection questions pre and post trip. The four pre-trip open-ended reflection questions included: what the students expected or hoped to learn, how they expected to learn this, the importance of this learning for their career skill development and how this learning could be used in the future. Upon completion of the service-learning experience, students were asked the same questions with slight variation- What did they learn, how did they learn this, the importance of this learning for career skill development and how this learning could be used in their future practice. Open coding strategies were employed to guide the researchers' analysis of the student participants' written responses. Results: There were 145 participants in the study, including 86 students in a comparison group and 59 students who participated in servicelearning trips during 2018 and 2019. Service-learning participants majored in nursing $(47.4 \%, n=28)$ and occupational therapy $(33.9 \%, n=20)$, with fewer participants in pharmacy $(n=5)$, physical therapy $(n=5)$ and social work $(n=2)$. Comparing pre and post service-learning group responses, researchers noted that the post-trip reflections included more depth, breadth and insight compared to the pretest reflection responses for each theme. Post trip responses also included the additional theme of personal growth. Post-trip participants reported having a greater self-awareness of their own limitations and strengths, having a broadened perspective, experiencing spiritual growth, and developing attitudes of gratefulness, humility, flexibility, patience, and empathy after participating in the trip, reinforcing the idea that immersion created learning is exponential when it is experiential. Conclusions: Service learning coupled with guided critical reflection is an effective tool in enhancing interprofessional collaboration. Qualitative analysis of students' self-reported learning through written reflections served as a valuable means for capturing learning outcomes related to interprofessional collaboration competencies.
\end{abstract}

\section{Author Bio(s)}

Tamara Lemmonds, EdD, OTR/L is the OTD Program Director and Assistant Professor in Occupational Therapy at Belmont University. Tamara is a pediatric occupational therapist in her $20^{\text {th }}$ year of practice. She had helped organize and lead thirteen faith-based, inter-professional mission trips to China and Guatemala.

Jamie Adam, DNP, RN, NP-C is an Associate Professor of Nursing at Belmont University. Jamie is a Family Nurse Practitioner and enjoys volunteering with interprofessional medical missions both locally and abroad. Each year she coordinates a faith-based inter-professional medical mission trip to Guatemala.

Elena Wong Espiritu, OTD, OTR/L, BCPR is an Associate Professor in the School of Occupational Therapy at Belmont University. Prior to academia, she participated in a number of mission trips and most recently led a service-learning trip to Haiti for occupational and physical therapy students.

David Wyant, assistant professor, Jack C. Massey College of Business, Belmont University, holds an MA (Economics) and MBA (Finance) from The Ohio State University, and a PhD in Health Services Research Policy and Administration from the University of Minnesota. He teaches Healthcare Information Technology, Statistics, and Healthcare Financial Management. 


\title{
IIIAHSP \\ The Internet Journal of Allied Health Sciences and Practice \\ Dedicated to allied health professional practice and education \\ Vol. 19 No. 3 ISSN 1540-580X
}

\section{Short-term Service-Learning: Implications for Preparing Health Science Students for Practice}

\author{
Tamara Lemmonds \\ Jamie Adam \\ Elena Wong Espiritu \\ David K. Wyant \\ Belmont Univeristy \\ United States
}

\begin{abstract}
Purpose: The purpose of this paper is to examine students' self-reported learning outcomes following participation in collaborative interprofessional service-learning experiences through the qualitative analysis of participants' written, guided critical reflections. Method: Participants responded to guided reflection questions pre and post trip. The four pre-trip open-ended reflection questions included: what the students expected or hoped to learn, how they expected to learn this, the importance of this learning for their career skill development and how this learning could be used in the future. Upon completion of the service-learning experience, students were asked the same questions with slight variation- What did they learn, how did they learn this, the importance of this learning for career skill development and how this learning could be used in their future practice. Open coding strategies were employed to guide the researchers' analysis of the student participants' written responses. Results: There were 145 participants in the study, including 86 students in a comparison group and 59 students who participated in service-learning trips during 2018 and 2019. Service-learning participants majored in nursing $(47.4 \%, n=28)$ and occupational therapy $(33.9 \%, n=20)$, with fewer participants in pharmacy $(n=5)$, physical therapy $(n=5)$ and social work $(n=2)$. Comparing pre and post service-learning group responses, researchers noted that the post-trip reflections included more depth, breadth and insight compared to the pretest reflection responses for each theme. Post trip responses also included the additional theme of personal growth. Post-trip participants reported having a greater self-awareness of their own limitations and strengths, having a broadened perspective, experiencing spiritual growth, and developing attitudes of gratefulness, humility, flexibility, patience, and empathy after participating in the trip, reinforcing the idea that immersion created learning is exponential when it is experiential. Conclusions: Service learning coupled with guided critical reflection is an effective tool in enhancing interprofessional collaboration. Qualitative analysis of students' self-reported learning through written reflections served as a valuable means for capturing learning outcomes related to interprofessional collaboration competencies.
\end{abstract}

Keywords: interprofessional education, interprofessional collaboration, service-learning, reflection, cultural immersion, short-term, SPICE-R2, DEAL 


\section{INTRODUCTION}

The purpose of this paper is to examine students' self-reported learning following participation in collaborative interprofessional service-learning experiences through the qualitative analysis of participants' written, guided critical reflections. In their early work on experiential education, Eyler and Giles introduced the concept of service-learning, describing it as a cycle that includes both action and reflection. ${ }^{1}$ They posited that as students engage in meaningful experiences in the community (action) and then reflect on those experiences, they deepen their own skills (learning). Hildenbrand and Schultz acknowledge that participant reflection is a powerful tool for examining the impact of student participation in service activities. ${ }^{2}$ Critical reflection is necessary to connect experience with learning objectives. Reflection, in other words, is the transformative cognitive process that makes meaning out of experience and creates the bridge between experience and learning. ${ }^{3}$ Service projects alone can immerse students in experience, but it is the reflection process that adds the learning component and ties the experience to academic objectives, deepening the value of the service project to become service-learning1. It should be noted that the quantitative results of the students' change in interprofessional knowledge, skills and attitudes as measured by the Students Perceptions of Physician-Pharmacist Interprofessional Education- Revised Version 2 (SPICE-R2) have been reported in another manuscript (J. Adam, DNP, T. Lemmonds, EdD, E. Espiritu, OTD, D. Wyant, PhD, unpublished manuscript, 2020).

\section{BACKGROUND}

\section{Interprofessional Education}

In the last decade, the Institute of Medicine (IOM) has highlighted the need for interprofessional teamwork to provide quality patient care. ${ }^{4}$ In 2011, the Interprofessional Education Collaborative (IPEC) requested that an expert panel identify specific interprofessional competencies essential for future health care professionals. ${ }^{5}$ Relevant to this study is the panel's claim that educational institutions need to "Find opportunities to integrate essential interprofessional education content consistent with current accreditation expectations for each health professions education program."6(p.8) In response to this initial charge, interprofessional education (IPE) has become a requirement for accreditation in most health sciences programs.7-12 Despite these mandates, academic institutions have struggled to navigate the pragmatic barriers of creating opportunities that both address the competencies and are meaningful to students. ${ }^{13}$

The World Health Organization (WHO) defines interprofessional collaboration as an opportunity "When two or more professions learn about, from, and with each other to enable effective collaboration and improve health outcomes." ${ }^{14}$ Learning about various healthcare professions is easily incorporated into didactic programming; however, learning from and with each, other proves to be more difficult. ${ }^{13}$ Logistical concerns such as scheduling, lack of access to other disciplines, and lack of shared curriculum or physical spaces impose barriers to IPE experiences. ${ }^{13}$ Service-learning opportunities conducted during school breaks reduce some of these barriers by typically occurring outside of regular curriculum. Intentional design of these service-learning experiences can offer multiple disciplines the opportunity to learn from and with each other as part of a health care team. Reflecting on the immersive service-learning experience helps students to build their knowledge of other professions while also facilitating competencies in working with and learning from their peers in other disciplines. ${ }^{15,16}$ The current premise of IPEC is that developing competence in interprofessional collaboration will ultimately strengthen teams and enhance patient outcomes. ${ }^{6}$ At the healthcare student level, educators can cultivate experiences to facilitate the development of interprofessional collaboration skill, even though the patient outcomes may not be directly measured during a student's time at the educational institution. ${ }^{4}$ More research needs to be done to measure the long-term effects collaboration has on patient care once clinicians enter the workforce.

The IOM's conceptual framework for measuring IPE outcomes include assessing student reactions, attitudes/perceptions, performance in practice, collaborative behavior, and knowledge/skills. ${ }^{4} \mathrm{~A}$ variety of quantitative instruments have been used to measure interprofessional learning, such as the Team Skills Scale (TSS) and Attitudes Toward Health Care Teams Scale (ATHCT), and more recently, the Students Perceptions of Interprofessional Clinical Education- Revised (SPICE-R).17,18,19 However, in recent years, the IOM has called upon health sciences programs to include qualitative measures, in addition to quantitative to assess interprofessional student learning outcomes. ${ }^{4}$ Qualitative research provides a method for exploring the "why" and "how" involved in IPE learning outcomes. Ideally, academic institutions are using both quantitative and qualitative measures when assessing IPE. ${ }^{20}$

\section{METHODOLOGY}

\section{Recruitment}

Students participating in the service-learning trips were invited to participate in the research study prior to trip departure. A purposeful comparison group of students in the Pharmacy, Physical Therapy, Occupational Therapy, Nursing and Social Work degree programs were also recruited by the faculty research team during the semester when the service-learning trips were offered. The students in the comparison group were intentionally selected to be similar in academic level (i.e. junior, senior, $1^{\text {st }}$ year, $2^{\text {nd }}$ year, etc.) and clinical experience to the cohort of students participating in the service-learning trips. This study was approved by 
the University IRB and written informed consent was obtained by all study participants prior to data collection. Student responses were de-identified.

\section{Instrument}

The DEAL model of critical reflection developed by Ash and Clayton, served to guide the development of the open-ended reflection questions. ${ }^{3}$ The four questions are listed in Table 1. Prior to this research study, the questions were piloted as student journal prompts and used to engage student reflection before and after service-learning trips that occurred during Spring break in both 2016 and 2017. While this allowed the questions to be pretested, the data from the pilot was not included in this study's data analysis. The pilot questions were modified to create the guided critical reflection template for this research study. Participants were provided with paper copies of the guided reflection questions.

Table 1. Interprofessional Service Learning Survey Questions

\begin{tabular}{|c|l|l|l|}
\hline Question & \multicolumn{1}{|c|}{ Pre-Service Learning } & \multicolumn{1}{c|}{ Post-Service Learning } & \multicolumn{1}{c|}{ DEAL Model } \\
\hline 1 & $\begin{array}{l}\text { What do you expect to learn on } \\
\text { this experience (about yourself, } \\
\text { your profession and role, clients, } \\
\text { colleagues, communities, } \\
\text { culture)? }\end{array}$ & $\begin{array}{l}\text { What did you learn on this } \\
\text { interprofessional intercultural immersion } \\
\text { experience? (about yourself, your } \\
\text { profession and role, clients, colleagues, } \\
\text { communities, culture)? }\end{array}$ & (D) Describe \\
\hline 2 & $\begin{array}{l}\text { How do you anticipate learning } \\
\text { this? }\end{array}$ & How did you learn this? & (E) Examine \\
\hline 3 & $\begin{array}{l}\text { Why will this be important for you } \\
\text { in developing your career skills? }\end{array}$ & $\begin{array}{l}\text { Why are these skill or attributes would } \\
\text { be important for you in developing your } \\
\text { career skills? }\end{array}$ & (AL) Articulate Learning \\
\hline 4 & $\begin{array}{l}\text { How will you be able to use what } \\
\text { you anticipate learning in your } \\
\text { future profession? }\end{array}$ & $\begin{array}{l}\text { How will you be able to use what you } \\
\text { learned in this interprofessional } \\
\text { intercultural immersion experience in } \\
\text { your future profession? }\end{array}$ & (AL) Articulate Learning \\
\hline
\end{tabular}

\section{Data Collection}

The University offered several faculty-led service learning opportunities to Cambodia, Guatemala, China, and Haiti in 2018 and 2019. The service-learning experiences ranged from seven days (Haiti, China), eight days (Guatemala) and 21 days (Cambodia). The Cambodia service-learning trip was also a study abroad course and had additional objectives related to public health concepts. Service-learning activities took place in low income, working poor areas of each country and are detailed in Table 2. All students participating on these trips in 2018 and 2019 were invited to participate in the research study. Students were invited to complete the open-ended survey measuring their perceived knowledge, attitudes, and skills about working with other disciplines prior to their service-learning experience. A comparison group of undergraduate and graduate students enrolled in the same health science programs but who did not participate in any of the cultural-immersion, service-learning trips were also asked to complete the openended survey prior to their classmates' participation on the service-learning trips. Pre-learning written responses were administered and collected from all participants in the week immediately preceding their scheduled trip. Participants completed the post-trip reflections either on the plane trips home or within the first week of their return. Participants did not have access to their initial responses while completing the post-trip surveys. All data was collected in hard copy format using paper documents over a twoyear period (2018-2019). Participation in the study was voluntary and students could opt out of participating in the study at any time.

\section{Data Analysis}

The students' written reflections on the open-ended survey served as the primary data set. The qualitative data collected in the written reflective responses allowed the researchers to appreciate the perceptions of students regarding the effects of cultural immersion service-learning on students' interprofessional knowledge, attitudes, and skills. Qualitative descriptive analysis was used to examine written reflections in the students' open-ended responses. According to Gay, Mills, and Airasian, qualitative descriptive analysis involves breaking down large quantities of data into smaller units through a coding process; then organizing the smaller units into themes. ${ }^{27}$ The themes found through the coding process spanned the four question responses. Themes identified through an open coding process were organized and analyzed by the researchers. ${ }^{28}$ Written reflections were analyzed in order by journal prompt question; therefore, the results are structured to report findings for each of the four respective reflection prompts. 
Table 2. Interprofessional Service Learning Activities

\begin{tabular}{|c|c|c|c|}
\hline CAMBODIA & CHINA & GUATEMALA & HAITI \\
\hline $\begin{array}{l}\text { Completed screenings: } \\
\text { blood pressure, blood sugar, } \\
\text { vision, hearing, height/weight } \\
\text { Provided education: oral } \\
\text { hygiene, hydration, } \\
\text { medication, safe lifting, body } \\
\text { mechanics } \\
\text { Provided child physicals } \\
\text { Provided ear irrigation }\end{array}$ & $\begin{array}{l}\text { Collaborated with staff at the } \\
\text { orphan care center to create } \\
\text { sensory boards for the } \\
\text { children's playroom. } \\
\text { Assembled mobile sensory- } \\
\text { play centers out of PVC pipe } \\
\text { to be used with the children } \\
\text { who are not independently } \\
\text { mobile. } \\
\text { Created and modeled } \\
\text { developmentally appropriate } \\
\text { play activities for the staff } \\
\text { and caretakers at the orphan } \\
\text { care center } \\
\text { Collaborated as a team, } \\
\text { including staff at the center, } \\
\text { to problem-solve current } \\
\text { feeding practices and safe- } \\
\text { feeding techniques. } \\
\text { Participated in cultural } \\
\text { classes together as a team. }\end{array}$ & $\begin{array}{l}\text { Completed screenings: blood } \\
\text { pressure, blood sugar, } \\
\text { height/weight } \\
\text { Provided education: } \\
\text { diabetes management, } \\
\text { hypertension, first } \\
\text { Aid/choking, medication } \\
\text { Musculoskeletal screenings } \\
\text { and education: safe lifting } \\
\text { stretching } \\
\text { Provided training and } \\
\text { education to therapy } \\
\text { caregivers of children with } \\
\text { disabilities. }\end{array}$ & $\begin{array}{l}\text { Constructed adaptive } \\
\text { equipment for children (e.g. } \\
\text { making adaptive seats out of } \\
5 \text { gallon buckets, making } \\
\text { standers out of duct tape } \\
\text { and PVC pipe) } \\
\text { Provided educational } \\
\text { session to OT/PT students at } \\
\text { a local university } \\
\text { Completed a case study with } \\
\text { Haitian rehabilitation } \\
\text { students } \\
\text { Provided fall risk } \\
\text { assessments for older adults } \\
\text { Planned and executed } \\
\text { activities for children with } \\
\text { disabilities and older adults }\end{array}$ \\
\hline
\end{tabular}

Open and focused coding strategies were employed to guide the researchers' analysis of the student participants' written responses to the open-ended, guided questions. Three researchers engaged in the coding process. Open coding allowed the researchers to identify similarities and differences through a first in-depth reading of the pre-and post-test open-ended surveys. ${ }^{28}$ Researchers worked in pairs during the first, second and third pass readings. Focused coding then enabled the researchers to identify themes; reanalyze the written responses and further refine the themes. ${ }^{29}$ Several broad categories emerged from the initial open-coding process. The initial dominant categories were IPE, cultural competence, healthcare systems, professional development, and personal growth. In pairs, the researchers employed an axial coding process; reading through the written responses a second time, line by line; organizing the text into the broad categories that emerged after the first reading. Identified categories were then complied in a table and the reflective responses were read a third time. During the third reading the researchers used the generated category table as a tally sheet to determine the frequency with which each theme was referenced in the students' written responses. All data and frequency tables generated from the focused coding process were reviewed by researcher pairs to increase rigor and reliability.

Detailed records of each step of the coding process were recorded in written format by the researchers and stored in a secured file. Records include who coded the data during each reading, the initial broad themes, tallies, and final emergent themes. In some cases, direct quotes from the students' reflective responses are shared as there were occasions where the participants' words clearly and powerfully conveyed ideas that could only be expressed verbatim.

\section{Participants}

There were 145 participants in the study, including 86 students in the comparison group and 59 students who participated in service-learning trips and completed the post-trip reflections during 2018 and 2019. The comparison group included 30 undergraduate and 56 graduate students. One hundred percent of trip participants $(n=63)$ consented to participate in the research study; however, four trip participants did not complete the post-trip reflections and therefore their data was omitted from the study. The final service-learning group was comprised of 59 students including 28 undergraduate and 31 graduate students. Among the service-learning group, $46.6 \%(n=27)$ had participated in at least one study abroad or a service-learning trip previously, compared to $36 \%(n=31)$ in the comparison group. The largest percentage of service-learning participants majored in nursing $(47.4 \%, n=28)$ and occupational therapy $(33.9 \%, n=20)$, with fewer participants in pharmacy $(n=5)$, physical therapy $(n=5)$ and social work $(n=2)$. 


\section{RESULTS}

\section{Qualitative Question Responses}

\section{Question \#1: Learning Expectations and Outcomes}

The first question was nuanced based on the grouping/timing of the survey. The comparison group answered the question "What would you expect to learn on this experience?" while the pre-survey question was "What do you hope to learn on this experience" and the post-trip survey question being "What did you learn on this experience?" The responses for all three surveys were similar, centering around four major themes: interprofessional education, cultural competence, professional growth/skills, and healthcare delivery.

Regarding IPE, the students thought that by participating in an international experience, they would gain a better understanding of other professions' scopes of practice and improve their collaboration and communication skills. Before going on a trip, one student said, "I want to learn the roles and power of a multidisciplinary team..." In contrasting his previous interprofessional educational experiences, a pharmacy student hoped to "learn how to actually work interprofessionally with nurse practitioner (NP) students, not just at educational events but with actual patients." The students who went on the trips also learned the importance of IPE for improved patient outcomes, learned to value and appreciate other professions by developing a trust in others and had a greater understanding of how to integrate other team members into their practice, seeing the value in the team's collective knowledge for improved patient care. One student said after participating in an international experience, "I never knew how easily we would be able to work together." Another student learned "...the importance of asking for advice from other professions."

The students had similar survey responses in what they expected and did learn related to cultural competence. They highlighted subthemes of knowledge and skills, comparing beliefs and values, and learning how to communicate with those that spoke a different language than themselves. Before going on a trip, a student hoped to "gain a new perspective on culture/cultural humility." Those who went on the trips anticipated and subsequently also gained having an appreciation for the cultural aspects of the trips. A student expressed this appreciation by stating, "Immersion is something l'll never be fearful of after this experience."

Professional growth and skill building were another common theme amongst survey responses, including opportunities for students to develop a better understanding of their own professional role while serving in another country, having opportunities for handson practice, and adapting when resources were limited. For one student, participating in an international trip took her out of her comfort zone; however, she recognized "...that is the best way to learn and grow." The students who went on the trips also reported an expectation of increasing their confidence in using their professional skills and post-trip reported developing more confidence as they had to think outside of the box and on their feet. A student described this shift in saying, "When I was stripped of resources, I had to think much harder and be creative." For a nursing student, her confidence improved when she realized, "These people were all there to see us and they trusted us. This made me feel like an actual nurse..."

The final common theme was healthcare delivery. The students believed they would learn and did learn about how healthcare is delivered in another country, experiencing the similarities and differences in how services are provided and availability of resources in the United States. Prior to her trip, a student wanted to learn "...how to treat patients who don't think and do things the same as I do." Another student expected "...to learn a new perspective of healthcare, want to learn how privileged I am..." Post-survey results also included learning about the value of patient-centered care and holistic approach. A student described this kind of care as "I learned many things, but most importantly that it's more about your patient's care, not about knowing everything."

One difference between the responses of the students in the comparison group versus the service-learning group was in the expectation and actual learning related to personal growth. Those who participated in the trips expected to not only grow professionally but also anticipated growing personally in their attitudes, having a willingness to learn, be out of their comfort zone and gain a new perspective on life by having an open mind and heart. Prior to taking a trip, a student described her openness to growth and development by saying, "I'm not sure what I'll learn about myself, but I know it will be profound. I plan to just be an open book, extra pair of hands, and whatever I need to be or do. I'm ready to be taught." These students reported having a greater self-awareness of their own limitations and strengths, having a broadened perspective, experiencing spiritual growth, and developing attitudes of gratefulness, humility, flexibility, patience, and empathy after participating in the trips. One student summarized her personal growth by saying, "I've learned so much about myself and l've really zoned into what God is calling me to do" and another student said, "I've learned that I need to do more internal work in order to best serve my patients."

Overall, for the first question, it appeared that the survey responses reflected a congruence between what the students thought they would learn, and what they did learn; however, after participating in an international immersion trip, the students' responses were more in-depth and centered around an appreciation for others and internal changes in attitudes and perspectives. 


\section{Question \#2: Learning Processes}

The second question asked the students how they expected to learn (pre-trip) and how they learned (post-trip) the items reported in question \#1. Responses were similar among the comparison group and service-learning group in regard to students expecting to learn by providing hands-on patient care together through team collaboration and immersing themselves into the culture by talking with and observing people. Service-learning participants provided additional insight into how they expected to learn about IPE and the culture, including team activities, pre-trip planning and researching in-country needs. Following the trip, the students reported having to "lean on each other," explain their roles to other team members and talking and listening to each other as other ways that they learned about IPE. One student described this reliance on each other by saying, "The stress of the environment necessitated that we all learned this. We didn't see much success until we began to work more as a unit." Finally, because those that participated in the trips anticipated and experienced personal growth, they suggested that this could be and was learned through attitudes and behaviors. Before her trip, a student said, "I will be open to doing whatever is asked of me, and I will be patient and not give up if I don't understand at first. I will try to make the most of every learning opportunity." Students reported that when they were open minded, intentional, and engaged, asked questions and listened to others and stepped out of their comfort zone, they expected and gained personal benefits from participating in the trips. One student's attitude was reflective in the statement "...being present. I want to soak up all the cultural experiences this trip offers."

\section{Question \#3: Skill Development and Attribute Acquisition}

Because this question was tied to the first question about what they expected/learned on the trips, the skills highlighted were similar: IPE, cultural competence, professional skills/growth and personal growth.

Overall, students thought that having opportunities for IPE would be beneficial in that they would have a better understanding of different professions' roles and scope of practice and improved communication leading to better patient outcomes. The servicelearning group noted both before and afterward that working on an interprofessional team was important for developing competence and confidence. After participating on the trip, the service-learning group also indicated that these experiences were important for learning how to respect other disciplines' roles and rely on others more. One student recognized that through interprofessional teamwork "...the number of resources and perspectives we have available to us through collaboration." Other students recognized the importance of asking for help by saying, "...this will make me more willing to call/work with each profession" and "it is okay to admit the limits of my scope of practice and to ask others for help."

Students also noted developing cultural competence as important for career development as they thought having a global perspective and awareness of other cultures while respecting and valuing other's beliefs and practices would be helpful in future client interactions. One student said, "It will help me think of healthcare in more of a global perspective."

The comparison group and service-learning group post-responses suggested that they would be better clinicians because of the experience. However, their responses differed in scope. The comparison group responses centered around understanding global service delivery, resource disparities and their own professional role and identity. One student who did not participate in the trips speculated that the experience "Will make me a more knowledgeable and informed clinician with a better perspective on the way in which our healthcare system compares/fits in with others around the world." In the service-learning group, post-trip, students also reported the importance of being a more effective clinician describing effective as having increased confidence, creativity and efficiency, realistic plans of care, and applying a therapeutic use of self to convey empathy and understanding. One occupational therapy student expressed a new understanding "...that interventions I think may be most beneficial may not fit into my client's life." A student who learned about orphan care during her trip to China said, "...gave me a new appreciation for 'walking in others' shoes."

Finally, both groups addressed personal growth as important for career skill development. They recognized that attitudes of empathy, humility, compassion, and selflessness as well as having an open heart and willingness to learn and charge were important for developing a broader perspective for their future careers. A service-learning student said, "I have gained insight that has reframed my clinical, spiritual, and personal mindset" and another student said, "I think it is important to be humbled by this experience."

\section{Question \#4: Impact on Future Profession}

The fourth question sought to determine how students thought that what they would learn or did learn would impact their future practice. The comparison and service-learning groups anticipated/discovered that they would use skills related to their profession, IPE and cultural competence in their future profession. Student responses included having an increased ability to problem solve both individually and as a team and understanding their own personal roles and the roles of other team members. The comparison group and service-learning group pre-trip responses focused on gaining knowledge of roles; however, the post-trip service-learning 
students expressed an appreciation and value for what other team members provided. In problem solving, all groups recognized that critical thinking was required while providing services, but the students who went on the trips, further described that their thinking was accompanied by improvisation, flexibility, adaptability, and "thinking outside of the box." The students who participated in the trips additionally suggested that they experienced personal growth which would impact their future role as a professional. The trips challenged students resulting in internal changes including changed attitudes and perspectives, being more flexible, handling stress and conflict and having "open hearts and minds" rather than casting judgement or bias. One student said, "...cultural values, foods, and traditions shape your patient. Therefore, it should shape our care." Another student expressed confidence posttrip knowing "I know that I can handle stress in almost any environment I am put into." A student profoundly reflected on her own shift in attitude by saying, "I think it is easy for Americans like myself to think that clients who are from low socioeconomic backgrounds (especially non-American) need 'saving' and that they are sad and that the whole situation is just depressing. I think going into a client/therapist relationship with that attitude creates a non-therapeutic power dynamic that does not lend itself well to trust and collaboration. - two things that are vital to success in therapy. I am going to try and be very cognizant of my attitude and opinions about clients from other cultures."

\section{DISCUSSION}

The themes captured in the pre-trip service-learning and comparison group reflections overlapped in their expectations for learning on a service-learning trip and how this would be helpful in their future career. Major themes in both groups included IPE, cultural competence, professional growth/skills, and healthcare delivery. However, comparing pre and post service-learning group responses revealed several interesting findings. Researchers noted that the post-trip service-learning reflection responses included more depth, breadth and insight compared to the pretest reflection responses for each of the themes. Post trip responses also included an additional major theme of personal growth. This group reported having a greater self-awareness of their own limitations and strengths, having a broadened perspective, experiencing spiritual growth, and developing attitudes of gratefulness, humility, flexibility, patience, and empathy after participating in the trip, reinforcing the idea that immersion created learning is exponential when it is experiential.

The service-learning group also learned to value and appreciate other professions by developing trust in others and had a greater understanding of how to integrate other team members into their practice, seeing the value in the team's collective knowledge for improved patient care. Additional themes included increased cultural knowledge, appreciation, understanding and communication skills. Professional growth and skill building were other common themes amongst survey responses, including opportunities for students to develop a better understanding of their own professional role within another country, having opportunities for handson practice and adapting when resources were limited. Students reported developing more confidence as they had to think "outside of the box" and "on their feet". The final common theme was healthcare delivery. Students reported understanding the value of patient centered care and a holistic approach.

Students reported that when they were open-minded, intentional, and engaged, asked questions, listened to others, and stepped out of their comfort zone, they expected and gained personal benefits from participating on the trips. In problem solving, both the service-learning and comparison groups recognized that critical thinking was required while providing services, but in the servicelearning post reflections, students further described that their thinking was accompanied by improvisation, flexibility, adaptability, and "thinking outside of the box."

The results of this study support the findings of previous research on service-learning as a tool for addressing interprofessional competencies. ${ }^{20,21}$ In addition, the themes noted in student reflections align with the Interprofessional Education Collaborative (IPEC) Core Competencies: 1) Values/Ethics for Interprofessional Practice, 2) Roles/Responsibilities, 3) Interprofessional Communication and 4) Teams and Teamwork. ${ }^{5}$

\section{CONCLUSION}

The results of this study highlight that service-learning, when coupled with guided critical reflection, serves as an effective tool for facilitating the development of interprofessional collaboration competencies in health professions students. The study also demonstrated the value of using qualitative methods to measure the impact of short-term interprofessional service-learning experiences through the lens of students' written reflections. Although this study was limited to students Belmont University, the results are congruent with the findings of studies completed at other institutions. $4,15,20$ Additional limitations to this study include a lack of diversity among trip participants and the small sample size of trip participants. Future research on this topic would benefit from soliciting participation from a more diverse student population; perhaps inviting participants from a variety of schools across the nation. Recommendation for future research includes a longitudinal study design that follows trip participants through their first five years as clinicians to examine whether learning outcomes from their trip participation affects patient outcomes. In addition, since the themes of this study support the IPEC competencies, future researchers may consider a study that compares the 
attitudes, skills and competencies of clinicians who participated in team-based learning opportunities such as the service-learning trip experiences and clinicians who studied interprofessional collaboration skills through another model." Interprofessional servicelearning experiences, when captured through guided reflection, can provide valuable insights into how and why students learn interprofessional competencies from and with each other.

\section{References}

1. Eyler J, Giles D. Where's the learning in service-learning? San Francisco, CA: Jossey-Bass; 1999.

2. Hildenbrand S, Schultz S. Implementing service learning in pre-service teacher coursework. J of Experiential Educ. 2015; 38(3): 262-279.

3. Ash SL, Clayton PH. Generating, deepening, and documenting learning: The power of critical reflection in applied learning. J Appl Learn High Educ. 2009;1:25-48.

4. Cox M, Cuff $P, B r a n d t ~ B$, et al. Measuring the impact of interprofessional education on collaborative practice and patient outcomes. J Interprof Care. 2016;30(1):1-3. doi: 10.3109/13561820.2015.1111052. [PMID: 26833103]

5. Interprofessional Education Collaborative. Core competencies for interprofessional collaborative practice: Report of an expert panel. Washington, D.C.: Interprofessional Education Collaborative, 2011.

6. Interprofessional Education Collaborative. Core competencies for interprofessional collaborative practice: 2016 update. Washington, DC: Interprofessional Education Collaborative, 2016.

7. Accreditation Council for Occupational Therapy Education: 2018 Accreditation Council for Occupational Therapy Education (ACOTE®) Standards and Interpretive Guide. https://acoteonline.org/wp-content/uploads/2020/10/2018-ACOTEStandards.pdf. Accessed March 13, 2021.

8. Commission on Accreditation in Physical Therapy Education: Standards and required elements for accreditation of physical therapy education programs. Updated November 10, $2020 \mathrm{https://www.capteonline.org/globalassets/capte-docs/capte-pt-}$ standards-required-elements.pdf. Accessed March 13, 2021.

9. American Association of Colleges of Nursing: Standards, procedures and guidelines. https://www.aacnnursing.org/CCNEAccreditation/Accreditation-Resources/Standards-Procedures-Guidelines. Accessed March 13, 2021.

10. Council on Social Work Education: Commission on accreditation department of social work accreditation 2015 EPASinterpretive guide. Updated February 24, 2021. https://www.cswe.org/CSWE/media/AccreditationPDFs/2015-EPASInterpretation-Guide-v-2-24-21-FINAL.pdf. Accessed March 13, 2021.

11. Accreditation Council for Pharmacy Education: Accreditation standards and key elements for the professional program in pharmacy leading to the doctor of pharmacy degree - standards 2016. https://www.acpeaccredit.org/pdf/Standards2016FINAL.pdf. Accessed March 13, 2021.

12. Zorek J, Raehl C. Interprofessional education accreditation standards in the USA: A comparative analysis. J Interprof Care. 2013 Mar;27(2):123-130. doi: 10.3109/13561820.2012.718295. [PMID: 22950791]

13. Lash DB, Barnett MJ, Parekh N, Shieh A, Louie MC, Tang TT. Perceived benefits and challenges of interprofessional education based on a multidisciplinary faculty member survey. Am J Pharm Educ. 2014;78(10):180. doi:10.5688/ajpe7810180.

14. World Health Organization: Framework for action on interprofessional education and collaborative practice.https://apps.who.int/iris/bitstream/handle/10665/70185/WHO_HRH_HPN_10.3_eng.pdf;jsessionid=2A3BDAB7B7F 473D2C682820E4579C58E?sequence=1. Accessed April 1, 2021.

15. Harvey M, Coulson D, McMaugh A. Towards a theory of the ecology of reflection: Reflective practice for experiential learning in higher education. J Univ Teach Learn Pract. 2016;13(2):1-20.

16. McNatt DB. Service-learning: An experiment to increase interpersonal communication confidence and competence. Educ Teach. 2019 Dec 18:62(2):129-144.

17. Hepburn, K., Tsukuda, R.A., \& Fasser, C. (2002). Team skill scale. In Heinemann, G. D., \& Zeiss, A. M. (Eds.), Team performance in health care: Assessment and development. (pp. 159-163). New York: Kluwer Academic/Plenum Publishers. https://nexusipe.org/informing/resource-center/tss-team-skills-scale

18. Heinemann G, Schmitt MH, Farrell M, et al. Development of an attitudes toward health care teams scale. Eval Health Prof. 1999 Mar;22(1):123-142. doi.10.1177/01632789922034202. [PMID 10350960]

19. Dominguez DG, Fike DS, MacLaughlin EJ, et al. A comparison of the validity of two instruments assessing health professional student perceptions of interprofessional education and practice. J Interprof Care. 2015 Mar;29(2):144-149. doi: 10.3109/13561820.2014.947360. [PMID 25101520]

20. Packard K, Ryan-Haddad A, Monaghan $M$ et al. Application of validated instruments to assess university-wide interprofessional service-learning experiences. J Interprof Educ Pract. 2016;4:69-75. doi: 10.1016/J.XJEP.2016.06.005 
21. Marcus MT, Taylor WC, Hormann MD, et al. Linking service-learning with community-based participatory research: An interprofessional course for health professional students. Nurs Outlook. 2011 Jan-Feb;59(1):47-54. doi:10.1016/j.outlook.2010.10.001. [PMID 21256362]

22. Kolb DA. Experiential learning; experience as the source of learning and development. Englewood Cliffs, NJ: Prentice Hall; 1984.

23. Mezirow J. Transformative learning theory. In Mezirow J, Taylor EW, eds. Transformative learning in practice: Insights from community, workplace, and higher education. San Franciso, CA: Jossey-Bass; 2009:18-31.

24. Gordijn F, Eernstoman N, Helder J, et al. Reflection methods: Practical guide for trainers and facilitators: Tools to make learning more meaningful. Available at: https://research.wur.nl/en/publications/reflection-methods-practical-guide-fortrainers-and-facilitators-. Accessed December 29, 2020.

25. Schon D. The reflective practitioner: How professionals think in action. London: Temple Smith; 1983.

26. Eyler J. Reflecting on service: Helping nursing students get the most from service-learning. J Nurs Educ. 2002 Oct;41(10):453-456. [PMID 12383003]

27. Gay LR, Mills GE, Airasian PW. Educational research competencies for analysis and application. $10^{\text {th }}$ ed. Columbus, $\mathrm{OH}$ : Pearson; 2011.

28. Corbin C, Strauss A. Basics of qualitative research: Techniques and procedures for developing grounded theory. Thousand Oaks, CA: Sage Publications; 2015.

29. Decarlo M. Scientific inquiry in social work. Pressbooks 2019. https://scientificinquiryinsocialwork.pressbooks.com/chapter/13-5-analyzing-qualitativedata/\#: :text=Focused\%20coding\%20is\%20a\%20multistage,be\%20related\%2C\%20perhaps\%20merging\%20some. Accessed April 2, 2021. 